\title{
Galvanic vestibular stimulation: a novel modulatory countermeasure for vestibular-associated movement disorders
}

\author{
Estimulação galvânica vestibular para corrigir transtornos neurológicos \\ associados à disfunção vestibular
}

Carlos V. Rizzo-Sierra ${ }^{1,2}$, Alexander Gonzalez-Castaño ${ }^{3}$, Fidias E. Leon-Sarmiento ${ }^{4,5}$

\begin{abstract}
Motion sickness or kinetosis is the result of the abnormal neural output originated by visual, proprioceptive and vestibular mismatch, which reverses once the dysfunctional sensory information becomes coherent. The space adaptation syndrome or space sickness relates to motion sickness; it is considered to be due to yaw, pith, and roll coordinates mismatch. Several behavioural and pharmacological measures have been proposed to control these vestibular-associated movement disorders with no success. Galvanic vestibular stimulation has the potential of up-regulating disturbed sensory-motor mismatch originated by kinetosis and space sickness by modulating the GABA-related ion channels neural transmission in the inner ear. It improves the signal-to-noise ratio of the afferent proprioceptive volleys, which would ultimately modulate the motor output restoring the disordered gait, balance and human locomotion due to kinetosis, as well as the spatial disorientation generated by gravity transition.
\end{abstract}

Keywords: kinetosis, spatial orientation, galvanic vestibular stimulation, movement disorders, space adaptation syndrome, GABA.

RESUMO

A cinetose ou doença do movimento resulta de uma resposta neural anormal originada do desequilíbrio entre estímulos visuais, proprioceptivos e vestibulares, que melhora quando esse desequilíbrio é corrigido. A síndrome de adaptação espacial ou doença do espaço está relacionada à doença do movimento e é desencadeada por mudanças bruscas de direção, inclinação e rotação da cabeça. Têm sido propostas várias medidas comportamentais e farmacológicas para controlar esses transtornos do movimento associados com o sistema vestibular, mas sem sucesso. A estimulação galvânica vestibular pode regular o desequilíbrio sensitivo-motor causado pela cinetose e pela doença do espaço modulando os canais iônicos GABA, relacionados à transmissão de impulsos nervosos no ouvido interno. Essa estimulação melhora a relação sinal-ruído dos impulsos proprioceptivos que acabam modulando a resposta motora, restabelecendo o equilíbrio e a marcha, recuperando a desorientação espacial causada pelos diversos gradientes de gravidade.

Palavras-chave: enjoo de movimento, orientação aeroespacial, estimulação galvânica vestibular, distúrbios do movimento, síndrome de adaptação aeroespacial, GABA.

Motion sickness (MS) or kinetosis is a sensory-motor dysfunction caused by a mismatch between the visually perceived movement and its neural integration with the proprioceptive and vestibular system ${ }^{1,2}$. As a result of this mismatch balance, gait and locomotion anomalies appear, which worsens the disabling dysautonomia that such mismatch originates $^{1,3-5}$. These neural disorders debut during land, marine, and aerospace motion, among others conditions ${ }^{1,2}$. MS can be developed in up to $39 \%$ of airplane pilot students ${ }^{6,7}$. Of remark, kinetosis is present in up to $91 \%$ of the human factors involved in aerial accidents ${ }^{3}$. Despite repeated exposure to environmental conditions simulating kinetosis, MS appears

\footnotetext{
${ }^{1}$ NeuroniKaS Laboratory, Advanced Biomedical Research Center, Bogota, Colombia;

${ }^{2}$ School of Industrial Engineering, SIGMMA, St. Thomas University, Bucaramanga, Colombia;

${ }^{3}$ Biosoft Research Group and Corporación Universitaria Minuto de Dios - Uniminuto, Bogota, Colombia;

4 Unit of Parkinson and Movement Disorders, Medi.ciencias, Unicolciencias/Universidad Nacional, Bogota, Colombia;

${ }^{5}$ Smell and Taste Center, Department of Otorhinolaryngology: Head and Neck Surgery, University of Pennsylvania, Philadelphia, PA, USA.

Correspondence: Fidias E. Leon-Sarmiento; Smell and Taste Center; Department of Otorhinolaryngology; Head and Neck Surgery; University of Pennsylvania;

Philadelphia PA - USA; E-mail: feleones@gmail.com

Conflict of interest: There is no conflict of interest to declare.

Support: Dr. Fidias E. Leon-Sarmiento was supported by the Department of Defense (Grant No.USAMRAA W81XWH-09-1-0467).

Received 30 March 2013, Received in final form 13 August 2013; Accepted 21 August 2013.
} 
in up to $70 \%$ of civilian and military airplane pilots while they are under training in flight simulators ${ }^{2,46}$. Although a good number of investigations have been done $e^{8}$, the pathophysiology of MS is far from understood.

Space adaptation syndrome (SAS) or space sickness, on the other hand, is a disorder that relates to MS, which is experienced by almost $50 \%$ of people traveling out of the Earth $^{4,6,8}$. It is believed that SAS is due to yaw, pith, and roll coordinates mismatch ${ }^{6,8}$. SAS accentuates with longer exposure to the stimulus that generates it, a situation that may lead to quit the career of the pilot at earlier times than planned $^{2,4,6}$. In addition, SAS possesses a risk of sudden disability in flight, as well as in the cabin of the plane ${ }^{6,8-10}$, among other menace ${ }^{11-15}$. Thus, SAS may endanger passengers, crew members and ground staff. In line with this, up to $29 \%$ of aerial accidents are considered to be due to the loss of control in aircrafts, most likely due to aerospace-related sickness ${ }^{3}$. Since not all airplanes' pilot and astronauts experience SAS, it is presumed that very elaborated mechanisms have to play a role to produce it. Among them, inherited point mutations of ionic channel structures in the inner ear canal, and ethnic differences still under looked are good candidates to lead the ion channels to become dysfunctional whenever gravity changes appear ${ }^{4,16}$. Whether these channel disorders are responsible for abnormal spreading of neuronal waves following gravity transition remains to be clarified, but it is intuitively possible ${ }^{17}$. It is also quite likely that individuals with the highly sensitive neurobiological trait are more vulnerable to be affected by SAS ${ }^{18,19}$. Despite the aforementioned theories postulated in the etiology of SAS $^{4,8,16,20}$, the precise mechanism for this disorder - similarly as it has happened in kinetosis - is still unclear.

\section{Current interventions in MS and SAS}

When individuals develop MS they show self-consistent patterns of pathophysiological variations that constitute a personal signature, which remains unchanged across multiple provocative exposures ${ }^{8}$. Thus, autogenic feedback training has been proposed as a measure to prevent space and terrestrial MS ${ }^{8}$. Using this technique, individuals are trained to detect subtle changes in heart rate, respiration, and skin temperature among other parameters ${ }^{8,21,22}$. People trained to keep in balance these physiological parameters are believed to become resistant to $\mathrm{MS}^{8,22}$. In theory, motion abnormalities originated by kinetosis should revert when visual, proprioceptive and vestibular input becomes coherent, which is the main goal of this type of intervention ${ }^{20,22}$. However, current studies indicate that astronauts do not benefit from autogenic feedback training, thus providing little hope that SAS as well as MS could be prevented or attenuated by this type of intervention?.

Pharmacological approaches have also been undertaken to control kinetosis and SAS, without success. For example, medications prescribed to airplane pilots for short periods of time during commercial flights, and under strict medical supervision ${ }^{22}$ have impaired their flight performance. Promethazine, the most common medication used to treat space sickness ${ }^{8}$, prevents adaptation or hinders learning. Thus, there is still concern that medications would delay sensory-motor adaptation in people exposed to aerospace environments, among other side effects ${ }^{8}$.

Similarly, interventions proposed to improve the quality of life of people suffering SAS have fallen short to prevent $\mathrm{it}^{6,21}$; further, they have also been inefficient to improve spatial disorientation and flight maneuverability ${ }^{2,6}$. Else, they are expensive and may affect aviation safety ${ }^{2,6,8}$. Of note, SAS re-appears on veteran astronauts during subsequent flights ${ }^{23}$. It means that this condition is resistant to habituation procedures $^{23}$, which parallels kinetosis-resistant habituation ${ }^{2,6}$.

Noteworthy, using a computational model, we recently demonstrated that gravity changes affect semicircular canals similarly as galvanic vestibular stimulation (GVS) does in humans, which in turn simulates SAS-like effects ${ }^{16}$. Of remark, the scientific literature is plenty of reports demonstrating the disordered motor output effects generated by GVS, and it is very scarce on the benefits that this non-invasive intervention may produce to humans. Interestingly, there is growing scientific evidence that supports the use of GVS as a novel and powerful neurorehabilitation measure in a number of movement disorders. Therefore, we anticipate that customized GVS can restore the abnormal human balance, gait and locomotion happening in the Earth, the moon, Mars and elsewhere.

\section{Technical aspects of GVS}

GVS is an non-invasive neural intervention developed since several centuries ago that is still overlooked in modern textbooks ${ }^{24,25}$. The galvanic stimulus is delivered by a controlled current source by means of a switch and a battery which usually does not exceed $9 \mathrm{~V}^{26}$. The current is delivered transcutaneously at levels of $\sim 1 \mathrm{~mA}$, which reaches vestibular afferents, modulating neural firing ${ }^{26,27}$. Although the stimulators used to generate the GVS are essentially similar, the changes in body perception, movement and spatial location that GVS produces are based upon wave configuration, polarity, intensity, duration, timing and frequency of the stimulation, and number and placement of the stimulating electrodes ${ }^{28-30}$.

Briefly, bilateral bipolar GVS is the mode most commonly used (Figure 1). In this case, the anode is placed on the mastoid process behind one ear, and the cathode behind the other ear ${ }^{27}$. The reference or ground signal is usually placed at the forehead. The signal originated from the semicircular canals during bilateral bipolar GVS mode originates a large roll and small yaw, both toward the cathodal side. Hence, the observed sway toward the anodal side appears to be the 

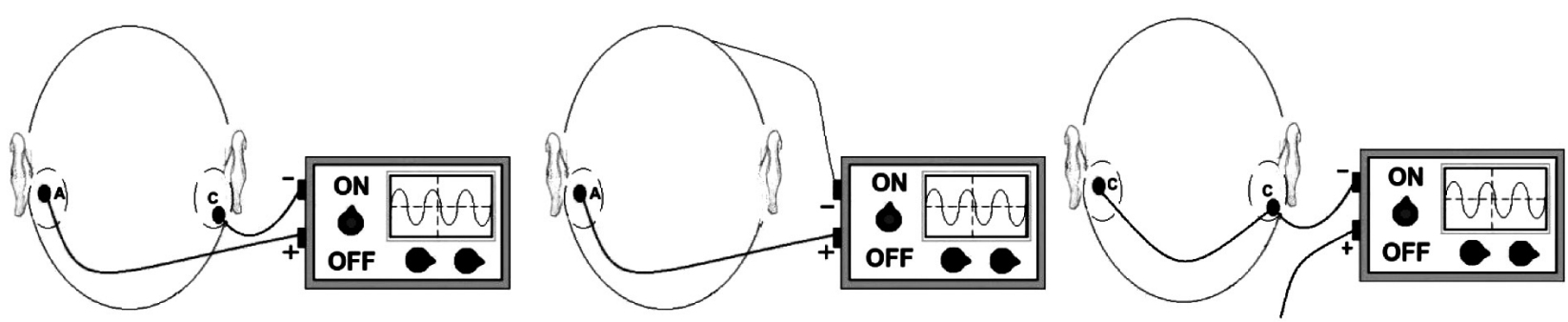

Figure 1. Schematic representation of GVS. Left: bilateral bipolar mode with the anode (A) and the cathode (C) placed retromastoideally. Center: unilateral mode with the cathode placed on the forehead. Right: bilateral monopolar mode with the anode placed elsewhere in the body. A sinusoidal current waveform is shown for didactic purposes.

appropriate balance response. Another type of stimulation is called bilateral monopolar. In this case, electrodes with the same polarity are placed in both ears, and a distant reference electrode is used. This type of GVS mode produces a semicircular canal signal of a small backward pitch with no roll component. Thus, the subjects sway forward with cathodal GVS on both sides and backward with anodal GVS on both sides. Another stimulation mode is called unilateral GVS mode. In this instance, the stimulating electrode is placed in one mastoid and the nonstimulating electrode is placed on the forehead, or in more distant regions such as the $\operatorname{arm}^{31}$. This mode of GVS evokes sway responses with an oblique trajectory $^{32,33}$. The lateral component of the oblique sway produced by unilateral GVS mode is either toward an anodal electrode or away from a cathodal electrode; however, the amount of sway is similar.

The galvanic current can also be modulated, with modifications owed to the aims of the study. In some cases, the stimulus is delivered in a continuous varying sinusoidal form ${ }^{34,35}$. In other occasions stochastic ${ }^{36,37}$ waveforms of alternating polarity have been used. These stimuli roughly modulate afferent firing similarly to the action exerted by the continuous tonic stimulus originated by the other modes of stimulation above mentioned.

\section{Neurofunctional aspects of GVS}

Very few or none adverse effects have been reported in humans; if any, they consist of mild sensations of transient retroauricular vibrations ${ }^{38-41}$. This makes GVS unique, compared to other vestibular modulatory stimulations such as the caloric one ${ }^{38-40}$. GVS polarizes the vestibular nerves, which means that GVS separates and accumulate positive and negative electric charges in two distinct regions of the mentioned nerves. This process activates the semicircular canals, otolith organs, and the adjacent vestibular nerves ${ }^{26,27}$. Thus, GVS modulates posture and balance relationship ${ }^{42-44}$, oculokinetic responses ${ }^{9,39}$ and spatial orientation ${ }^{45}$. The action of GVS has been modeled using vector summation, following stimulation of the pars medialis, bilateral utricular macular and semicircular canals ${ }^{38}$. Such modeling has demonstrated that vector summation from utricular afferents does not explain the observed sway in people exposed to GVS. Therefore, new hypotheses have been proposed. Some of them have suggested that the otolithic component involved in the balance response originates only from the pars medialis of the utricular macula ${ }^{26}$. Further, functional neuroimaging studies have revealed the existence of a complex network of multisensory cortical areas activated by GVS in healthy and ill populations. Such areas include the insular and retroinsular regions, the superior temporal gyrus, temporo-parietal cortex, the basal ganglia and the anterior cingulate gyrus ${ }^{46,47}$. The parietoinsular vestibular cortex and the temporo-parietal junction area are activated as well in healthy subjects. Interestingly, bilateral activations of vestibular cortices are obtained by applying left-cathodal/right-anodal GVS, whereas unilateral, right-hemispheric activations are induced by right-cathodal/ left-anoidal GVS ${ }^{46,48}$.

\section{Mechanisms of GVS}

GVS applied at spaced intervals ${ }^{27}$ may control abnormal movements secondary to MS, SAS and the like. This would be possible by modulating aberrant action potentials that happen in the sensory-motor mismatch ${ }^{4,16}$, which follows the abnormal neural re-firing originated by these disorders ${ }^{4,49,50}$. The restorative action of GVS can be due to the time dependent electric field embedded system that has the potential of modulating GABA receptor signaling given its electromagnetic properties ${ }^{51}$. As it is widely known, GABA is the main inhibitory neurotransmitter of the mammalian central nervous system that regulates neuronal excitability ${ }^{52}$. In the vestibular end organ, in particular, GABA modulates vestibular afferent nerve firing ${ }^{50,52}$. Recent research demonstrated that the GABAergic component of the olivocochlear system also contributes to the long-term homeostasis of key hair cells and related neuronsin the inner ear, which are needed to keep human balance in place ${ }^{53}$. Likewise, GVS modulates inhibitory activity recorded from the lateral vestibulo-spinal tract and from the spinal motor neuron activity, all of which is linked to GABAergic neural distribution ${ }^{54}$. Furthermore, the GABAergic system found in the choclea 
and inner ear ${ }^{49,55}$ also plays an important role in the efferent modulation of balance and locomotion, postural stability and muscle ton $e^{52,53,56}$, which has been measured by different means including transcranial magnetic stimulation ${ }^{57,58}$.

Of remark, GVS would also help to restore balance, gait, equilibrium and locomotion in humans affected not only by MS or SAS, but also by the sensory and motor mismatch following neurodegenerative conditions ${ }^{27,56}$. The fact that GVS improves the disordered sensorimotor activity by modulating the abnormal sensoperceptual ${ }^{29,30}$ afferent information along with the disturbed motor output in patients with disabling neural disorders, including Parkinson's disease ${ }^{59,60}$, normal pressure hydrocephalus ${ }^{61}$ (Leon-Sarmiento et al., unpublished observations), and focal dystonia ${ }^{40,62}$ supports this view. To prove more efficiently these assumptions, we re-analyzed the results of the effects of GVS in a patient with cervical dystonia ${ }^{40}$.

\section{GVS and movement disorders}

The effects of GVS in the neck muscles of a patient with focal dystonia were mathematically calculated. We measured the number of spikes of at least $50 \mu \mathrm{V}$ of amplitude ${ }^{63}$ before and after the application of $\mathrm{GVS}^{40}$. The galvanic stimuli were up to $2.5 \mathrm{~mA}$ square wave direct current steps of $20-\mathrm{msec}$ duration. The stimuli were generated by an isolated stimulator (Model DS2A; Digitimer, Ltd., Hertfordshire, UK) and delivered to the mastoid processes at a rate of $3 \mathrm{~Hz}$, by means of $20 \mathrm{~cm}^{2}$ self-adhesive electrodes, which were cut from electrosurgical plating (3M, St. Paul, MN) and coated with electrode ge ${ }^{40}$. The current was delivered with the cathode at the left mastoid and anode at the right, or vice-versa ${ }^{40}$. After GVS intervention, it was very impressive to observe that the muscle activity displayed by this patient before the intervention, which was $9.2 \mathrm{~Hz}$, was significantly reduced to $1.4 \mathrm{~Hz}$, after intervention ( $t$ test, $\mathrm{p}<0.05$ ) (Figure 2). The most likely explanation for such improvement seemed to be on the benefits exerted in the short latency afferents of the vestibule and trigeminal cervical pathways ${ }^{64-66}$ of this patient. Of remark, these neural pathways use GABA as one of their main neurotransmitters as well ${ }^{67}$.

Recently, limited studies also reported the benefits exerted by the application of GVS in patients with Parkinson's disease. In one case, a patient who complained of camptocornia received a single session of GVS. Binaural monopolar GVS was applied for 20 minutes. In this stimulation mode, the cathode electrode was placed over each the mastoid process and the anode electrode over the trapezius muscle. Immediately after GVS application, the trunk flexion angle was reduced by $32.1 \%$ compared with the values obtained before GVS. This improvement lasted for a month ${ }^{68}$. Another study ${ }^{69}$ used bicathodal GVS in five patients with Parkinson's disease. This GVS configuration employs two cathodal mastoid electrodes and one anodal electrode at the $\mathrm{C} 7$ vertebra.

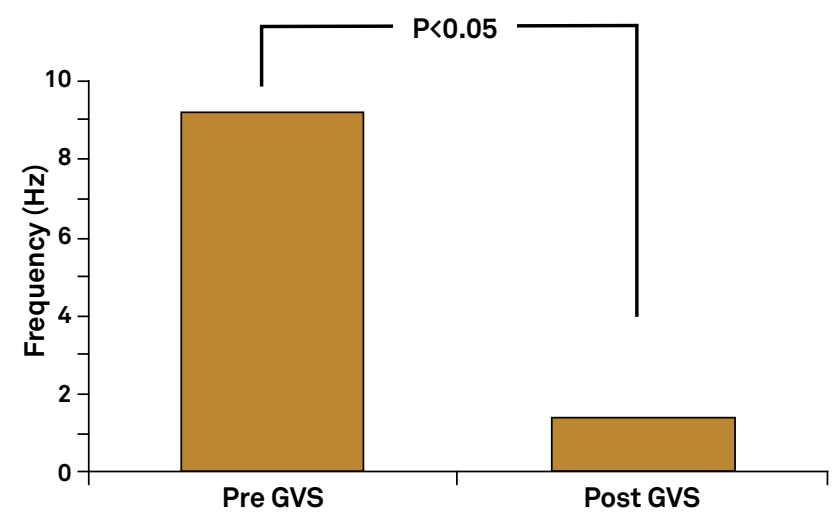

Figure 2. Electromyographic activity recorded in the right sternocleidomastoid muscle before (left) and after (right) intervention. Note the significant decrease of the muscle activity after applying GVS (modified from ref. 40).

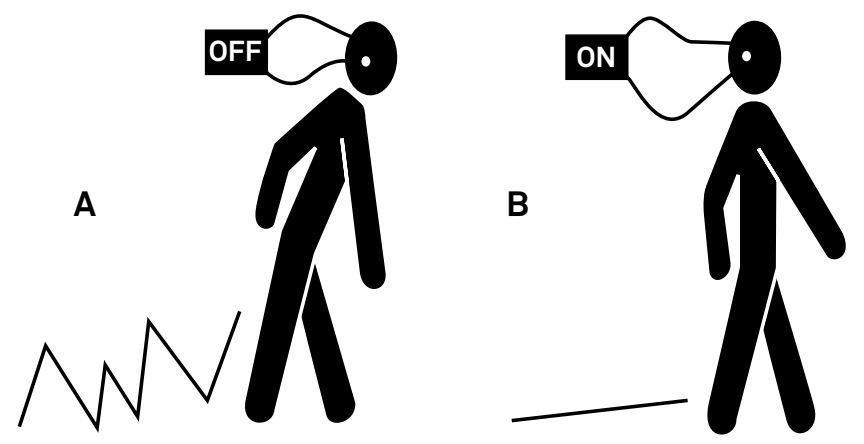

Figure 3. Schematic representation of the proposed beneficial effects exerted by GVS in human gait and locomotion. The zig-zag gait recorded from a patient with gait disturbances, while the stimulator is OFF (A) turns to be straight when the stimulator is ON (B) (see text for details).

It was found that $0.1 \mathrm{~mA}$ stochastic current reduced the body sway of the patients. The aforementioned results are encouraging to implement novel GVS methodologies looking to improve balance and gait in Parkinson's disease via modulation of the cholinergic system, without the side effects brought about by classical pharmacological interventions.

\section{Concluding remarks}

The easiness, low cost and portability makes GVS a novel countermeasure for restoring abnormal balance, gait and human locomotion in individuals living in different gravity conditions, including the Earth, the moon and elsewhere. In addition, given the encouraging results of GVS in improving motor function in humans ${ }^{25,70}$, we stress out the potential of employing GVS in the rehabilitation of hypoand hyperkinetic disorders, including those associated to brain and spinal cord injury as well as neurodegeneration that happens at different levels of the neuroaxis ${ }^{71,72}$. We 
anticipate that novel vestibular neurorehabilitation and sensorimotor control of human balance, gait and locomotion would be at hand in a near future by customizing GVS interventions. Sooner than later, turning GVS devices ON will make a good number of disabling vestibular-associated neural disorders to turn OFF! (Figure 3).

\section{Acknowlegments}

The authors would like to thank the assistance to an earlier version of this manuscript done by Carolina Valderrama, Melina Ariza, Evan Beals and Daniel S. Leon-Ariza. The guidance and support received from Dr. Richard L. Doty, Dr. Hongasandra R. Nagendra and Eng. Jaime Diaz are also greatly appreciated.

\section{References}

1. Shupak A, Gordon C. Motion sickness: advances in pathogenesis, prediction, prevention, and treatment. Aviat Space Environ Med 2006;77:1213-1223.

2. Rainford D, Gradwell D. Ernsting's Aviation Medicine, $3^{\text {rd }}$ Ed., London, Hodder Arnold, 2006.

3. National transportation safety board (NTSB). Annual Review of General Aviation Accident Data 2005, NTSB, Washington DC, 2009.

4. Rizzo-Sierra CV, Leon-Sarmiento FE. Pathophysiology of movement disorders due to gravity transitions: The channelopathy linkage in human balance and locomotion. Med Hypoth 2011;77:97-100.

5. Valderrama C, Calderón A, Malpica D, Leon-Sarmiento FE. Non invasive autonomous evaluation: proven priciples and posible practices. Actual Enferm 2007;10:17-24.

6. Davis J, Johnson R, StepanekJ, Fogarty J. Fundamentals of Aerospace Medicine, $4^{\text {th }}$ Ed., Houston (TX), Lippincott Williams and Wilkins, 2008.

7. Lucertini M, Lugli V, Casagrande M, Trivelloni P. Effects of airsickness in male and female student pilots: adaptation rates and 4-year outcomes. Aviat Space Environ Med 2008;79:677-684.

8. Lackner J, DiZio P. Space motion sickness. Exp Brain Res 2006;175:377-399.

9. Valderrama C, Álvarez C. Transmission of diseases in comercial flights: from myth to reality. Infectio 2009;13:203-216.

10. Valderrama C, Feijo D, Gil C, Jiménez E, Leon-Sarmiento FE. Medicine for the colombian airplane passenger ¿lf not now, when then? Acta Med Col 2008;33:150-152.

11. Forster E, Whinnery J, Antunano M, Valderrama C. Coronary artery disease in airline transport pilots: part 1 of 2. Aviat Space Environ Med 2010;81:323.

12. Leon-Sarmiento FE, Valderrama C, Calderón A, Malpica D, Fajardo H. Headache in flights: Takeoff and landing of a new clinical entity. Rev Fac Med 2008;56:77-79.

13. Leon-Sarmiento FE, Valderrama C, Malpica D, Calderon A. Airplane headaches: time to classify them. Headache 2008;48:165-166.

14. Valderrama C. Who is who? Aeromedical implications of gender dysphoria. Fed Air Surgeon's Med Bull 2009;47:6-7.

15. Valderrama C, Forster E. Coronary artery disease in airline transport pilots: part 2 of 2. Aviat Space Environ Med 2010;81:323.

16. Leon-Sarmiento FE, Rizzo-Sierra CV, Gonzalez-Castaño A. Modeling the effects of gravity transitions in the vestibular system: Preliminary findings. Neurology 2012;78(Suppl):S6-S42.

17. Wiedemann M, Hanke W. Gravity sensing in the central nervous system. J Gravit Physiol 2002;9:43-44.

18. Rizzo-Sierra CV, Leon-S M, Leon-Sarmiento FE. Higher sensory processing sensitivity, introversion and ectomorphism: New biomarkers for human creativity in developing rural areas $\mathrm{J}$ Neurosci Rural Pract 2012;3:159-162.

19. Rizzo-Sierra CV, Duran M, Leon-Sarmiento FE. Highly sensitive trait and ectomorphism: another link on creativity and psychopathology. Can J Psychiatry 2011;56:702-703.
20. Legner K. Humans in space \& space biology, United Nations office for outer space affairs, Vienna, 2003.

21. Zajonc T, Roland P. Vertigo and motion sickness. Part I: vestibular anatomy and physiology. Ear Nose Throat J 2005; 58:1-4.

22. Zajonc T, Roland P.Vertigo and motion sickness. Part II pharmacologic treatment. Ear Nose Throat J 2006;85:25-35.

23. Freeman M. Challenges of human space exploration, Chichester (West Sussex), Praxis Publishing, 2006.

24. Wassermann E, Epstein C, Ziemann U, Walsh V, Paus T, Lisanby S. The Oxford Handbook of Transcranial Stimulation, Oxford, Oxford University Press, 2008.

25. Lisanby S. Brain stimulation in Psychiatry treatment, Arlington, American Psychiatric Publishing, 2004.

26. Fitzpatrick R, Day B. Probing the human vestibular system with galvanic stimulation. J Appl Physiol 2004;96:2301-2316.

27. Pan W, Soma R, Kwak S, Yamamoto Y. Improvement of motor functions by noisy vestibular stimulation in central neurodegenerative disorders. J Neurol 2008;255:1657-1661.

28. Ghanim Z, LamyJ, LackmyA, et al. Effects of galvanic mastoid stimulation in seated human subjects. J Appl Physiol 2009;106:893-903.

29. Kennedy $P$, Inglis $T$. Interaction effects of galvanic vestibular stimulation and head position on the soleus $\mathrm{H}$ reflex in humans. Clin Neurophysiol 2002;113:1709-1714.

30. Saj A, Honore J, Rousseaux M. Perception of the vertical in patients with right hemispheric lesion: Effect of galvanic vestibular stimulation. Neuropsychologia 2006;44:1509-1512.

31. Tokita $\mathrm{T}$, Ito $\mathrm{Y}$, Miyata $\mathrm{H}$, Koizumi $\mathrm{H}$. Labyrinthine control of upright posture in humans. In: Tokita T, Ito Y, Miyata H, Koizumi H (Eds.). Progress in Brain Research. Amsterdam: Elsevier 1988:291-295.

32. Severac Cauquil A, Gervet MF, Ouaknine M. Body response to binaural monopolar galvanic vestibular stimulation in humans. Neurosci Lett 1998;245:37-40.

33. Severac Cauquil A, Martinez P, Ouaknine M, Tardy-Gervet MF. Orientation of the body response to galvanic stimulation as a function of the inter-vestibular imbalance. Exp Brain Res 2000;133: 501-505.

34. Coats $A$. The sinusoidal galvanic body-sway response. Acta Otolaryngol 1972;74:155-162.

35. Petersen H, Magnusson M, Fransson PA, Johansson R. Vestibular disturbance at frequencies above $1 \mathrm{~Hz}$ affects human postural control. Acta Otolaryngol 1994;114:225-230.

36. Fitzpatrick R, Burke D, Gandevia SC. Loop gain of reflexes controlling human standing measured with the use of postural and vestibular disturbances. J Neurophysiol 1996;76:3994-4008.

37. Pavlik AE, Inglis JT, Lauk M, Oddsson L, Collins JJ. The effects of stochastic galvanic vestibular stimulation on human postural sway. Exp Brain Res 1999;124:273-280.

38. Murofushi T, Iwasaki S, Ozeki H, Ushio M, Chihara Y. Tone burstgalvanic ratio of vestibular evoked myogenic potential amplitudes: a new parameter of vestibular evoked myogenic potential? Clin Neurophysiol 2007;118:1685-1690. 
39. Murofushi T, Takegoshi H, Ohki H, Ozeki H. Galvanic-evoked myogenic responses in patients with an absence of click-evoked vestibulocollic reflexes. Clin Neurophysiol 2002;113:305-309.

40. Rosengren S, Colebatch J. Cervical dystonia responsive to acoustic and galvanic vestibular stimulation. Mov Disord 2006;21:1495-1499.

41. Rorsman I, Magnusson M, Johansson B. Reduction of visuo-spatial neglect with vestibular galvanic stimulation. Scand J Rehab Med 1999;31:117-124.

42. Orlov I, Stolbkov Y, Shuplyakov V. Effects of artificial feedback to the vestibular input on postural instability induced by asymmetric proprioceptive stimulation. Neurosci Behav Physiol 2008;38:195-201.

43. Balter S, Castelijns M, Stokroos R, Kingma H. Galvanic-induced body sway in vestibular schwannoma patients: evidence for stimulation of the central vestibular system. Acta Otolaryngol 2004;124:1015-1021.

44. Monobe $\mathrm{H}$, Murofushi T. Vestibular testing by electrical stimulation in patients with unilateral vestibular deafferentation: galvanic evoked myogenic responses testing versus galvanic body sway testing. Clin Neurophysiol 2004;11:807-811.

45. Moore S, MacDougall H, Peters B, Bloomberg J, Curthoys I, Cohen H. Modeling locomotor dysfunction following spaceflight with galvanic vestibular stimulation. Exp Brain Res 2006;174:647-659.

46. Utz K, Dimova V, Oppenländer K, Kerkhoff G. Electrified minds: transcranial direct current stimulation (tDCS) and galvanic vestibular stimulation (GVS) as methods of non-invasive brain stimulation in neuropsychology, a review of current data and future implications. Neuropsychologia 2010;48:2789-2810.

47. Lobel E, Kleine J.F, Bihan D.L, Leroy-Willig A, Berthoz A. Functional MRI of galvanic vestibular stimulation. J Neurophysiol 1998;80:2699-2709.

48. Dieterich M, Bense S, Lutz S, et al. Dominance for vestibular cortical function in the non-dominant hemisphere. Cereb Cortex 2003;13:994-1007.

49. Zheng $H$, Qin X, Fu Y. Detection of GABAA alpha 2 mRNA in rat vestibular end organ with in-situ hybridization. Zhonghua Er Bi Yan Hou Ke Za Zhi 2001;36:190-192.

50. Leon-Sarmiento FE, Bayona-Prieto J, Gomez J. Neurophysiology of blepharospasm and multiple system atrophy: clues to its pathophysiology. Parkinsonism Relat Disord 2005;11:199-201.

51. Farrant M, Kaila K. The cellular, molecular and ionic basis of GABA (A) receptor signalling. Ptog Brain Res 2007;160:59-87.

52. Watanabe M, Maemura K, Kanbara K, Tamayama T, Hatasaki H. GABA and GABA receptors in the central nervous system and other organs. Int Rev Cytol 2002;213:1-47.

53. Maison S, Rosahl T, Homanics G, Liberman M. Functional role of GABAergic innervation of the cochlea: phenotypic analysis of mice lacking GABA receptor subunits. J Neurosci 2006;26:10315-10326.

54. OkamiK,SekitaniT,OgataM,etal.GABAdistribution in the centralvestibular system after retroauricular galvanic stimulation. An immunohistochemical study. Acta Otolaryngol 1991;481(Suppl):S150-S152.
55. Kempf H, Brandle T, Wisden W, Zenner H, Marx A. Detection of GABA(A) receptor $m R N A$ in cochlear tissue, an in situ hybridization study. HNO 1995;43:12-18.

56. Tjernström F, Bagher A, Fransson P. Short and long-term postural learning to withstand galvanic vestibular perturbations. J Vestibular Research 2010;20:407-417.

57. Leon-Sarmiento FE, Granadillo E, Bayona EA. Present and future of the transcranial magnetic stimulation. Inv Clin 2013;54:74-89.

58. Marsden J, Playford D, Day B. The vestibular control of balance after stroke. J Neurol Neurosurg Psychiatry 2005;76:670-678.

59. Samoudi G, Nissbrandt H, Dutia M, Bergquist F. Noisy galvanic vestibular stimulation promotes GABA release in the substantia nigra and improves locomotion in hemiparkinsonian rats. PloS One 2012;7:1.

60. Leon-Sarmiento FE, Rizzo-Sierra CV, Bayona E, Bayona-Prieto J, Doty R, Bara-Jimenez W. Novel mechanisms underlying inhibitory and facilitatory transcranial magnetic stimulation abnormalities in Parkinson's disease. Arch Med Res 2013;44:221-228.

61. Leon-Sarmiento FE, Pradilla G, Zambrano M. Primary and reversible Pisa syndrome in juvenile normal pressure hydrocephalus. Acta Neuropsychiatry 2013;25:57-60.

62. Bohlhalter S, Leon-Sarmiento FE, Hallett M. Abnormality of motor cortex excitability in peripherally induced dystonia. Mov Disord 2007;22:1186-1189.

63. Battaglia F, Ghilardi MF, Quartarone A, Bagnato S, Girlanda P, Hallett M. Impaired long-term potentiation-like plasticity of the trigeminal blink reflex circuit in Parkinson's disease. Mov Disord 2006;21:2230-2233.

64. Abrahams VC, Kori AA, Loeb GE, Richmond FJ, Rose PK, Keirstead SA Facial input to neck motoneurons: trigemino-cervical reflexes in the conscious and anaesthetised cat. Exp Brain Res 1993;97:23-30.

65. Ertekin C, Celebisoy N, Uludağ B. Trigemino-cervical reflexes in normal subjects. J Neurol Sci 1996;143:84-90.

66. Deriu F, Tolu E, Rothwell JC. A short latency vestibulomasseteric reflex evoked by electrical stimulation over the mastoid in healthy humans. J Physiol 2003;553:267-279.

67. Chana P, de Marinis A, Barrientos N. Gabapentin and motor fluctuations in Parkinson's disease. Mov Disord 1997;12:608.

68. Okada Y, kita Y, Nakmura J, Tanizawa M, Morimoto S, Shomoto K Galvanic vestibular stimulation for camptocormia in Parkinson's disease. J Nov Physiother 2012:S1:1.

69. Pal S, Rosengren SM, Colebatch JG. Stochastic galvanic vestibular stimulation produces a small reduction in sway in Parkinson's disease. J Vestib Res 2009;19:137-142.

70. Scinicariello A, Eaton K, Inglis J, Collins J. Enhancing human balance control with galvanic vestibular stimulation. Biol Cybern 2001;84:475-480.

71. Bayona-Prieto J, Bayona E, Leon-Sarmiento FE. Neuroplasticity, neuromodulation and neurorehabilitation: Three different concepts, one only true goal. Salud Uninorte 2011;27:95-107.

72. Bayona-Prieto J, Bayona E, Leon-Sarmiento FE. Neurorehabilitation: from a rigid past to a plastic future. Gac Med Mex 2012;48:91-96. 